\title{
Towards Balanced Discussions in the Classroom using Ambient Information Visualisations
}

\begin{abstract}
In a collaborative learning environment, the promotion and support of well-balanced student participation is an important step towards the achievement of learning outcomes. Ambient information visualisations can help raise awareness of the balance of distribution in meetings and small learner groups. This paper explores the use of ambient information in the classroom, where we attempt to encourage a proper balance of feedback between student groups during "design critique" studio sessions. The contribution of the paper is two-fold: i) it presents necessary design choices for ambient visualisations that promote feedback balance in classrooms, motivating under-participators while limiting over-participation, and ii) it shows the effects on student perception and feedback participation through the actual deployment of such visualisations in "real classroom sessions".
\end{abstract}

Keywords: learning analytics, ambient displays, ambient information visualisation, discussion participation, design critique, participation balance, awareness, classroom learning activities

\section{Introduction}

Learning Analytics, or the collection and analysis of traces that learners leave behind, can help to understand and optimize (human) learning and learning environments (Siemens \& Long, 2011). Furthermore, it can help to raise awareness of personal and peer learning activities, help reflect on and make sense of learner traces, and impact behaviour (Verbert, Duval, Klerkx, Govaerts, \& Santos, 2013). These traces can reflect activities inside and outside the classroom (Santos et al., 2013) of both students and teachers, but can also be used to impact activities in a live classroom. It allows teachers to intervene or orchestrate (Martinez-Maldonado, Kay, Yacef, \& Schwendimann, 2012), and students to become aware of their behaviour and progress on tasks (Dillenbourg et al., 2011).

In this paper, we focus on visualising learning analytics live in two Master courses at KU Leuven, Belgium: "Information Visualisation" (IV) and "Fundamentals of Computer-Human Interaction" (FCHI). In these courses, students work in group to design, implement, present and iterate on information visualisations in the former, and to develop a mobile game in the latter. The courses put a large emphasis on peer review, teaching students how to evaluate and discuss their designs and technical implementations, in a community of practice (Wenger, 2011). This is supported through the use of blogs that helps students report and share opinions and knowledge (Marques, Krejci, Siqueira, Pimentel, \& Braz, 2013). As communication and collaboration skills are key 21 st century competences for lifelong learning (Lee, Tsai, Chai, \& Koh, 2014), "design critique" face-to-face sessions are organised where students present their group's progress to the class and provide feedback to each other on their intermediate results.

Over- and under-participation in collaborative learning settings can reduce motivation and lower learning outcomes (Salomon \& Globerson, 1989). Literature has shown that ambient displays are an effective means to tone down over-participators and motivate underparticipators (Bachour, Kaplan, \& Dillenbourg, 2010). As such, they can help achieve a better balance by raising awareness of participation distribution in meetings and small learner groups. 
This work goes a step further. By placing an ambient information visualisation (AIV) (Skog, Ljungblad, \& Erik Holmquist, 2003) that visualises participation distribution in a nondistractive way, we investigate if and how it can promote balanced feedback participation in larger learning groups during repeated face-to-face "design critique sessions" in the classroom. Two case studies were carried out toward that goal.

The first case study explores and evaluates four visualisation designs to raise awareness of balanced discussion in the classroom. The second case study improves the first case study's most promising design and investigates students' perception of its impact in the classroom. The gathered analytics data of the two case studies are used to investigate the effect on feedback balance. More specifically, we aim to answer the following research questions:

- (RQ1) What are the design challenges for AIVs to promote balanced group participation in classrooms, and how can they be met?

- (RQ2) Are visualisations on ambient displays effective means for creating balanced group participation in classroom settings?

The paper starts by explaining the state of the art in Section 2, and how our work attempts to contribute to it. Section 3 explains the methodology and briefly discusses the technical implementation. Section 4 describes the design choices, elaborates on the different visualisations for our AIVs, and reports on the evaluation results of the first case study. Section 5 builds upon the findings of the first case study and reports on the evaluation results of the second case study, including students' perception of having such an AIV in the classroom. Section 6 reports on the actual effects on discussion balance during both case studies. Section 7 and 8 discuss our general findings and reflect on opportunities for future work.

\section{Related Work}

Communication and collaboration skills are key 21 st century competences for lifelong learning (Lee et al., 2014). We focus specifically on the former in "design critique" sessions where on average four to seven teams of three students present their work to each other and receive indepth feedback from their peers. The quality of the feedback students give to their peers correlates positively with the quality of their own work (Li, Liu, \& Steckelberg, 2010). It is thus important to promote this activity in the classroom. Lack of balance in participation can however negatively impact collaborative learning (Salomon \& Globerson, 1989): Overparticipation of a learner can affect others to "free-ride", while the "free-riders" can affect the motivated learner to reduce contributions. Over-participation can lead to a group dominating the conversation, giving other groups no chance to contribute.

Group mirrors (Bergstrom \& Karahalios, 2007c) are systems that can shed light on the distribution and thus type (presentation, interview, meeting) of group discussion participation through real-time visualisations (Scott, Tomadaki, \& Quick, 2007). Pentland et al. (2012) use personal devices to visualise discussion balance by showing discussion dominance in a "tug of war" fashion, resulting in improved cooperation for distributed groups. Occhialini et al. (2011) designed halogen spots to shed light on time management in meetings. DiMicco et al. (J. M. DiMicco, Pandolfo, \& Bender, 2004; JoanMorris DiMicco \& Bender, 2007) present discussion activities as bar charts, circle sizes and time-lines on walls and small tabletop devices, helping over-participators stay aware and tone down their activities. Schiavo et al. (2014) explore ways of creating more subtle interventions to guide discussions through peripheral displays. A natural discussion setting, such as sitting around a table, can be augmented with participation distribution by visualising the data on the table's surface (Bachour et al., 2010; Bergstrom \& 
Karahalios, 2007a). These examples show that peripheral visualisations of discussion activities can directly influence participation.

The previous examples focus on creating awareness of individuals' participation. Visualisations can furthermore enhance classroom orchestration and participation in learning activities of student teams, by making the invisible factors in the classroom visible (Dillenbourg et al., 2011). MTDashboard (Martinez-Maldonado, Clayphan, Yacef, \& Kay, 2014) provides teachers with a private view on group's activities and progress, to facilitate intervention. Lantern (a multi-LED device) and Shelf (a central dashboard) visualise the group's working and time waiting for teaching assistants (TA), informing TAs which groups to attend to first (Dillenbourg et al., 2011). These public visualisations also create a mutual awareness of activities and progress between teams. Paulus \& Dzindolet (1993) found that knowledge about other group's brainstorm performance could influence participation behaviour. Similarly, the awareness created by "Learning Dashboards" (i.e. visual representations of learning analytics) can lead to specific learning impact (Verbert et al., 2014).

This work attempts to leverage the use of ambient displays to create balance in participation of during discussion sessions in the class room. Wisneski et al. (1998) defines ambient displays as a way of moving information into the environment, hereby allowing the user to switch between their main focus and peripheral information. Pousman \& Stasko (2006) pitched the term ambient information systems, adding that the information represented should be important but not critical, the display environmentally appropriate, subtle with updates and tangible. Some examples mentioned above fall into this category: Lanterns (Dillenbourg et al., 2011) help students become aware of surrounding peer progress. Occhialini et al. (2011) augment the peripheral environment through halogen spots information with time management data.

Ambient displays are still best known for being physicial in nature. The first occurance is assumed to be the Dangling String (Weiser \& Brown, 1996), notifying co-workers about network traffic through a moving string hung from the ceiling. More recent examples are Ambient Rabbits (Mirlacher, Buchner, Förster, Weiss, \& Tscheligi, 2009) visualising weather forecast, AwareMirror, augmented mirrors (Fujinami, Kawsar, \& Nakajima, 2005) providing personal information during morning bathroom activities, and Gleamy (Cha, Lee, \& Nam, 2016), a bedside lamp visualing daily activity. Skog et al. (2003) argue ambient displays should not necessarily be physical in nature. Both small displays such as mobile phones (van Tonder \& Wesson, 2008), as well as large displays (Hinrichs, Fisher, \& Riche, 2010) are suitable for ambient information systems, and can display artistic (Skog et al., 2003;Eades \& Shen, 2004;Miller \& Stasko, 2002), informative (Hinrichs et al., 2010) and more traditional visualisations (J. M. DiMicco et al., 2004; JoanMorris DiMicco \& Bender, 2007). These AIVs (Skog et al., 2003) move information visualization applications from the desktop computer screen into the environment or periphery of the user. Similarly, our work uses large displays and wall projections in the classroom, to display information visualisations regarding balance of participation. The focus of the design is thus not on the physical, but on the digital information on the screen. While it does not match the tangible characteristic of Pousman \& Stasko (2006)'s definition, it takes every other aspect into account: the display visualises information regarding participation balance (important but not critical information), it is projected/displayed on a screen and thus already part of the classroom structure (environmentally appropriate), next to the presenting students (in the periphery, see Figure 2), and we focus on keeping the distraction low (updates subtly). 
To quantify oral participation, Pentland et al. (2012) measured length and speed of talking, vowel and pause counting. Tausch et al. (2015) manually measure the number of contributions. DiMicco et al. (2004) used length of speaking time to effectively tone down over-participators. For the purpose of our evaluation study, we use length of speaking time as measure for the quantity of participation in the discussion. The quality of participation e.g. correctness, relatedness, value, is more difficult to measure. Conversation Votes (Bergstrom \& Karahalios, 2007b) lets participants vote anonymously on peer contribution. As students can benefit from synchronous peer feedback (Pavlou \& Kyza, 2013), we briefly explore live peer-assessment through a "like" voting system.

During the "design critique" classroom sessions, giving feedback is an important learning activity. A balanced feedback session would give each group equal chances to practice this skill. By creating group mirrors to visualise these learning activities, i.e. each group's feedback participation, this work attempts to raise awareness regarding the feedback distribution. This awareness can in turn assist in toning down over-participators and motivating underparticipators, resulting in a better balance of practicing feedback.

\section{Methodology}

Our evaluation study consists of two case studies performed in two Master courses where the classroom sessions are structured around "design critique": Each group gives a presentation of their project, after which the other groups provide critical feedback and ask questions for clarification. The professor and teaching assistants act as facilitators and provide feedback.

Our focus lies first and foremost on the usefulness and effects of the visualisations in the classroom. We therefore use a Wizard of Oz approach (Green \& Wei-Haas, 1985): instead of automatically gathering the amount of feedback given by each group through microphones and audio processing, in our approach a TA uses a simple web interface to capture when each group starts and stops talking (see Figure 1).

\begin{tabular}{|c|c|}
\hline The InfoVisioneers & Set presenter \\
\hline LWM & Set presenter \\
\hline Invisual & Set presenter \\
\hline Data Chartists & Set presenter \\
\hline Prof/TA & Set presenter \\
\hline
\end{tabular}

Figure 1 Wizard of Oz interface: The TA sets a group as presenter to initialize the visualisation. When a group starts providing feedback, the TA clicks the group's name. When the group stops talking, the TA clicks the name again.

The first case study, "Designs", focuses on the design challenges for the AIV. Four designs are deployed and evaluated during an IV course session. These designs visualise both quantitative and qualitative data regarding the feedback participation. The second case study "Promoting Balance" focusses on the most promising design of the first case study and explores students' perception regarding the visualisation of participation balance. This visualisation was deployed and evaluated during a FCHI course. Quality of feedback was recorded but not visualised during the second case study. Feedback activities were logged during both case studies and were further analysed to get insights into the effects of the AIV on the feedback balance in the classroom. 
The visualisations are presented on a large display that is positioned in front of the classroom, next to the students who are presenting their work and receiving feedback (see Figure 2). The web interface was developed in HTML, CSS and JavaScript. The visualisations are developed using Processing.js ${ }^{1}$. A Node.js ${ }^{2}$ server using Socket. $\mathrm{IO}^{3}$ provides real-time communication between all applications. All events are furthermore stored in $\mathrm{MongoDB}^{4}$ for posteriori analysis.

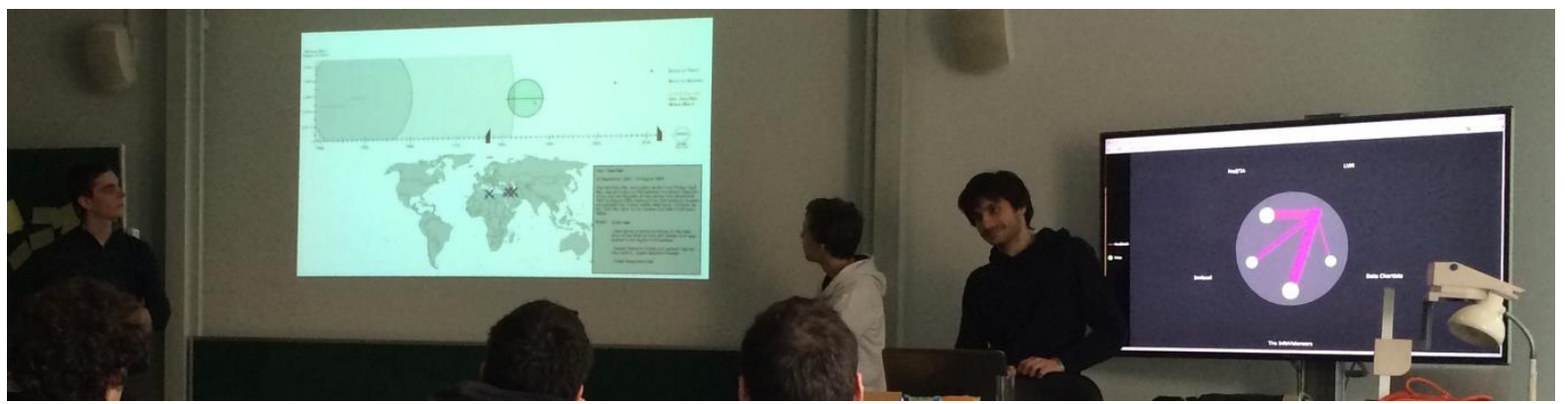

Figure 2 Students presenting their work. On the right, a large display provides live information on feedback balance.

\section{Case Study 1: Designs}

\section{Requirements and Design Choices}

Our goal is to find out if we can use AIVs to i) create a more balanced discussion by raising awareness about the balance of quantity and quality of the feedback, and ii) that are perceived useful and are accepted by students for further use in the classroom.

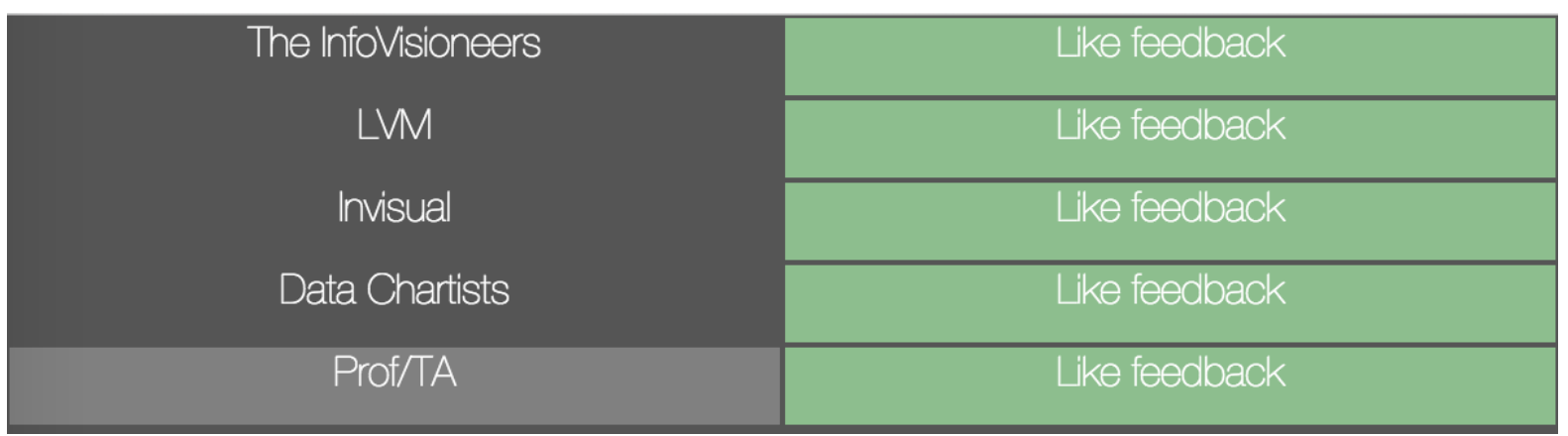

Figure 3 Screenshot of a web interface that enables a student to rate a group anonymously. A "like" can be sent during and after the feedback was given.

A class discussion was held during an IV course session to introduce the concept of visualising feedback participation through AIVs and gather preliminary feedback. During the first case study, we wished to briefly explore adding a qualitative aspect to the visualisation. We proposed a rating system with which students could rate peer feedback. Students responded that they prefer a positive rating system, as they did not feel comfortable with giving and receiving negative peer ratings. This led us to implement a "like" system. Each student can access a web interface (see Figure 3) with which the student can send a "like" to any other group as an appreciation of their questions or comments.

\footnotetext{
${ }^{1} \mathrm{http}: / /$ processingjs.org

$2 \mathrm{http}: / /$ nodejs.org

${ }^{3} \mathrm{http}: / /$ socket.io

${ }^{4} \mathrm{http} / / /$ www.mongodb.org
} 
To arrive at a successful design, we follow Pousman \& Stasko (2006)'s taxonomy of four design dimensions for ambient information systems: information capacity (IC), notification level (NL), representational fidelity (RF), and aesthetic emphasis (AE). IC indicates the number of different information sources that a system can represent. NL is the degree to which the system interrupts the user. RF is the abstraction of the data, with fidelity ranging from symbolic (low) to indexical (high, e.g. a map). AE deals with the importance of aesthetics put into the system, i.e. whether being visually pleasing is a primary objective.

The information we thus wish to portray is limited to two attributes per participating group: the quantity (duration) and quality of feedback ("likes") given after a single presentation. These attributes will show the current balance status of the group discussion, not its evolution through time. This keeps IC requirements low. Our case study needs to visualize the feedback of five groups during the length of one presentation. However, the designs discussed can easily be extended to facilitate more groups and longer sessions.

Students should be made aware of the (im)balance of feedback quantity and quality, so that they can adjust their behaviour. To adhere to the ambient nature of the visualisation, NL must remain low, so that the main focus remains on the students who are presenting their work or the other students providing feedback. Information updates must thus be subtle, but apparent enough to support awareness of the balance situation.

Regarding RF, we explore different abstractions to portray the data. We hypothesise that it is not important to show exact numbers of the balance to communicate the situation regarding feedback balance in the classroom.

Our visualisations will be most effective when students accept their presence in the classroom. AE is therefore important as it can influence the attitude towards the AIV (Tractinsky \& Eytam, 2012). 


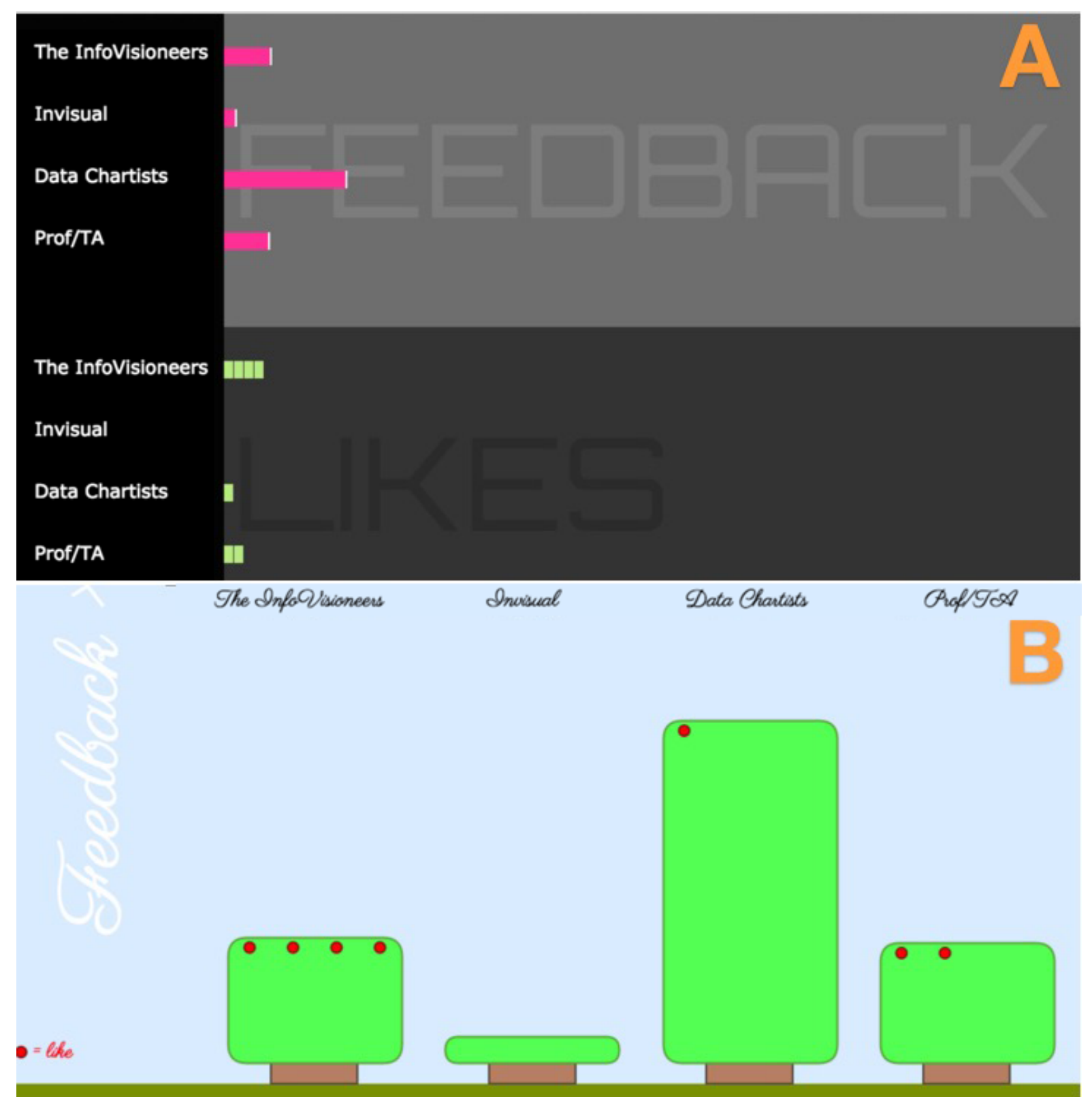

Figure 4 A. Using length to visualise quantity of feedback given and number of "likes" received. Top bars represent feedback; bottom bars represent "likes". B. Trees as a substitute for bars. Apples represent the number of "likes" a group has received.

\section{Proposed Designs}

Based on the discussions with the students, two attributes must be visualised: likes and participation. Adhering to the dimensions proposed by Pousman \& Stasko (2006), we designed four dashboards that were deployed in the classroom for evaluation purposes in a realistic setting. Version A provides a direct visualisation of the data through bar charts (RF focus on quantity). Version B's presents a playful approach of version A (AE focus). Version $\mathrm{C}$ adds group interaction to the visualisation (higher IC focus). Version $\mathrm{D}$ abstracts the quantitative participation information into a balance representation (RF focus on balance).

\section{Version A - Bars}

A straightforward way of presenting the distribution of feedback is through a histogram (see Figure 4.A). The quantity of feedback that a group provides is represented by the length of a bar in the top part of the visualisation. When a group gives feedback, its "feedback bar" grows. Similarly, when a group receives a "like" for its feedback from another group, its "like" bar 
grows by one segment in the bottom part of the visualisation. As mentioned above, exact numbers are not important but the representation of balance, under- and over-participation is. Here, a balanced discussion with regards to both quality and quantity is indicated by bars of roughly equal length.

Version B - Trees

Similar to A and inspired by Nakahara et al. (2005), each "feedback" bar is replaced by a tree representing the group, creating a more "playful" visualisation (see Figure 4.B) where each tree grows in size as the corresponding group provides more feedback. Apples are added to a tree for every "like" the corresponding group receives. Balance is now indicated by similar height of trees and equal distribution of apples.

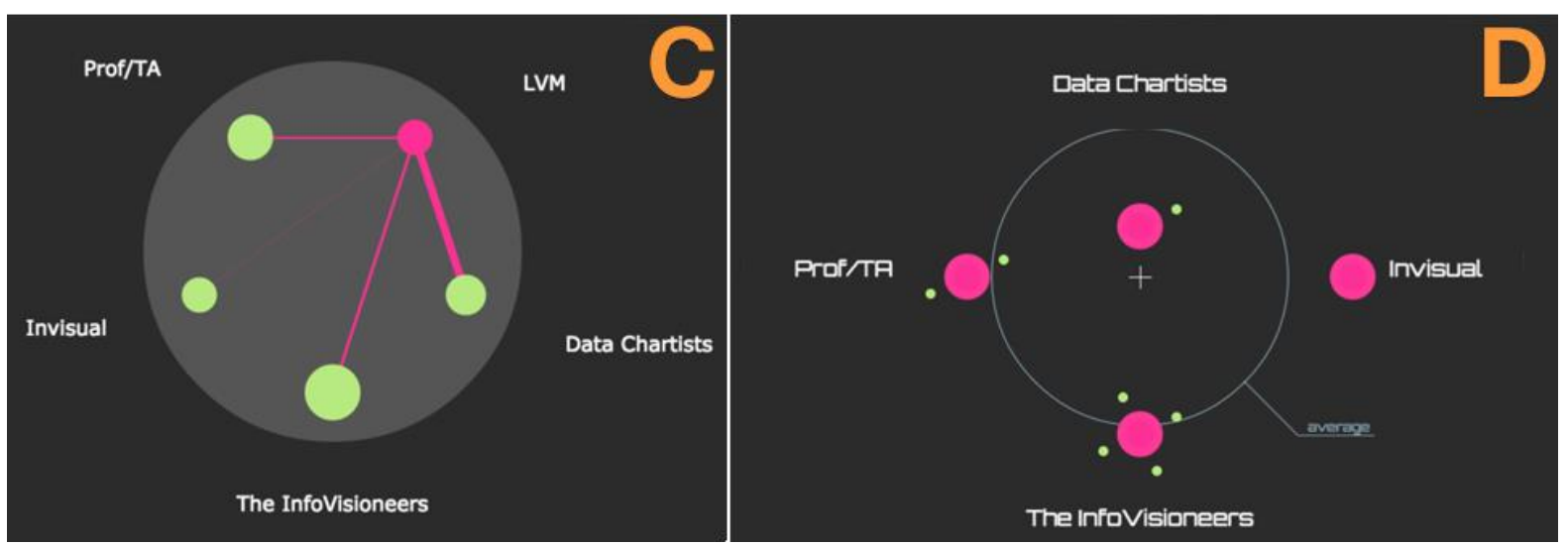

Figure 5 C. Every circle represents a group. The pink circle is the group presenting; the green circles are the groups giving feedback. The amount of feedback a group gives is visualised by the thickness of the line between the group and the presenters. The size of the circle indicates the number of likes received. D. Each group is indicated by a circle. The large white circle represents the average amount of feedback across the groups. Groups must try to stay on the outer rim to keep balance within the classroom discussion. Green orbiting dots are the "likes" received by the group.

\section{Version C - Node-Link Graph}

Every group is represented by a large dot (see Figure 5.C). The presenting group is indicated by the pink dot. (Note that this is the only visualisation where the presenter is also visualised). The presenter dot is static, as this group does not receive "likes" and does not give feedback. All other groups are visualised by green dots. A green dot grows in size as the group receives more "likes". The width of the line between the presenter and a group represents the quantity of feedback. As the group provides feedback, the line is animated by growing in width (visualising length of total feedback) and fades in and out (the group is actively talking). Equal line widths (quantity) and dot sizes (quality) between all green dots indicate a balanced discussion.

\section{Version D - Average}

The audience groups giving feedback are represented by pink dots (see Figure 5.D). Each dot is positioned on a large white circle that defines the average amount of feedback given across all groups. At the start of a session, contribution is 0 across all groups, thus all groups rest on the circle (average $=0$ ).

Changes in group feedback balance affect the group dots, while the average circle remains static. When a group gives feedback, all dots are moved according to their distance from the average: the dot for the active group moves to the centre of the circle and inactive groups are pushed outwards. "Likes" are indicated by smaller, green dots that orbit around the pink dot 
representing the group whose feedback is being liked. Balance is achieved when all groups are located close to the circle, with an equal distribution of orbiting "like" dots.

\section{Evaluation}

\section{Experiment Setup}

We evaluated our visualisation design choices (focussed on NL, AE, RF. IC is limited to two parameters) (Pousman \& Stasko, 2006) on perceived awareness of and its usefulness for creating balance of feedback.

During a "design critique" session of the IV course at KU Leuven, twelve students (four groups of three students, age 21-23, all male) each present the results of their work progress. All groups in the audience, including the teacher and TA "group" provide feedback and questions. Students access the feedback web interface (see Figure 3) to send "likes" to peer groups. For our evaluation, one teacher assistant used the simple tracking interface (see Figure 1) to log the start and end times of the feedback. The display, a 60-inch TV positioned next to the presenting students, displayed a single design per presentation.

After every feedback session, the students were asked to fill in a questionnaire (C1Q1) with four questions (Q1.1-Q1.4) that used a 5-Likert scale questions (never, rarely, sometimes, often, always - strongly disagree, disagree, neither agree or disagree, agree, strongly agree) and an open question (Q1.5) regarding likes and dislikes about the visualisations.

Q1.1. How often did you look at the visualisation?

Q1.2. Was the visualisation distracting?

Q1.3. The visualisation gave me a good indication of the quality of each group's feedback/questions.

Q1.4. The visualisation gave me a good indication whether or not the distribution of feedback among groups was well balanced.

Q1.5. What did you like/dislike about the visualisation?

After the design critique studio session, students filled in another questionnaire (C1Q2). They were asked to order the four visualisations: by clarity for visualising balance of quantity (through length of time giving feedback), clarity for visualising balance of quality (through number of likes each groups received), aesthetic preference, distraction level and general preference.

To validate the use of AIVs for the purpose of better balance and to get a better understanding of students' attitude towards the public sharing of this information, five more 5-Likert scale questions (strongly disagree, disagree, neither agree or disagree, agree, strongly agree) were asked.

Q2.1. Were you uncomfortable to see your group's feedback information shared?

Q2.2. Would you want such visualisation to be present in other discussion settings? (e.g. other classes?)

Q2.3. Would you prefer this information to be shared personally, instead of on a more public display? (e.g. through notifications, personal device etc.)

Q2.4. Do you think this personal approach will be as effective as a public visualisation?

$\mathrm{Q} 2.5$. Do you think such visualisations helps a discussion setting? 
A confirmative answer on question C1Q2.1, i.e. the student was uncomfortable with the visualisation, was followed by requesting the student to rank the visualisations by level of discomfort.

The next section will present the general student perception regarding our AIVs in the classroom. Then we will go into more detail on the per-visualisation evaluation results.

\section{General Perception of the AIV}

The general consensus was that the AIV has a perceived impact on participation during feedback (see Figure 6, C1Q2.5). Investigating individual questionnaire results, overparticipating groups perceived it as a motivational tool, while under-participating groups experienced it (more negatively) as pressure. Three out of twelve students, all from groups with lower participation, experienced the visualisations as uncomfortable.

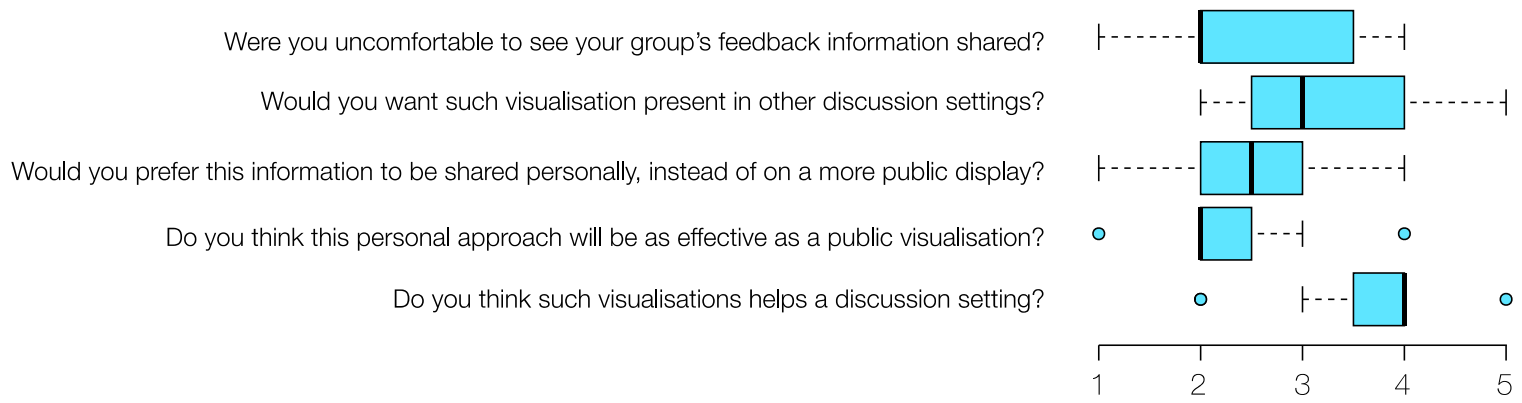

Figure 6 Results of the questionnaire ( $N=12)$ regarding all visualisations, at the end of the studio session (C1Q2).

The public nature of the visualisations on an AIV was well received (see Figure 6, C1Q2.3-45): seven students would not prefer a more personalized approach, such as visualisations on personal devices or personal notifications. Nine students did not think such a personal approach would be as efficient. Nine students were convinced the visualisations are very effective for discussion sessions. Five students would want to see such visualisations used in other discussion settings.

\section{Visualisation-Specific Results}

Based on the resulting student order of the visualisations (see Table 1) and the C1Q1 questionnaire results (see Figure 7), this section discusses three design dimensions NL, RF and AE (Pousman \& Stasko 2006). We elaborate further on the results in the Discussion section.

Notification Level. A low NL is necessary to avoid distracting students too much from the actual "design critique" process. Distraction rated high for visualisation B and C. Students mentioned that visualisation C's indication of an active group (by fading in and out their feedback line, see Version C - Node-Link Graph) called too much for attention. Visualisations D and A were perceived as less distracting. While visualisation $\mathrm{D}$ also uses animation, its subtler nature (slow movement of dots, slow orbiting "likes") seemed less obtrusive in calling for attention. Students reported to look at each visualisation, with a frequency lower for D and A.

Representational Fidelity. All visualisations scored well regarding clarity of balance and clarity of quality. Students rated visualisations A and B highest for clarity. C rated lowest: students found deducing balance by comparing dot size and line width difficult. Over-participators (identified through the logged feedback activity data and matched to their questionnaire results) perceived receiving "likes" as motivational. One student mentioned: "It made me want to 
continue giving feedback for more likes". While visualisation D rated lower than A and B for clarity of quality, students experienced the orbiting "likes" as rewarding and fun; visualisation A was experienced as "boring".

RF design choices can impact the way the data is perceived. Three out of twelve students experienced the visualisations as uncomfortable. D was experienced as most uncomfortable, while A as least. Visualisation D's ideal situation (i.e. balance) is not what students seem to aim for. More contribution by a group moves their dot inwards, while pushing other groups outwards. The under-participators' distance from the average circle is quickly experienced as insurmountable. The "playful" nature of B was described as "less threatening" by less participating groups, and "fun" and "rewarding" by active groups.

Aesthetic Emphasis. Emphasis on AE can make the visualisation more enjoyable and help improve acceptance of the visualisation. Visualisations $\mathrm{C}$ and $\mathrm{D}$ rated highest for aesthetic preference. Preference for further use of such visualisations (e.g. in other discussion settings) went to versions $\mathrm{A}$ and $\mathrm{D}$.

Table 1 Students' ordering of the visualisation by: clarity quantity balance, clarity of quality balance, aesthetic preference, level of distraction, how uncomfortable they felt and general preference.

\begin{tabular}{|c|c|c|c|c|c|c|}
\cline { 2 - 7 } \multicolumn{1}{c|}{} & Clarity of Balance & Clarity of Likes & Aesthetics & Distracting & Uncomfortable & Preference \\
\hline$A$ & $\mathbf{1}$ & $\mathbf{1}$ & 4 & 4 & 3 & 2 \\
\hline$B$ & 2 & 2 & 3 & $\mathbf{1}$ & 2 & 4 \\
\hline$C$ & 4 & 4 & 2 & 2 & 2 & 3 \\
\hline$D$ & 3 & 3 & $\mathbf{1}$ & 3 & $\mathbf{1}$ & $\mathbf{1}$ \\
\hline
\end{tabular}

How often did you look?

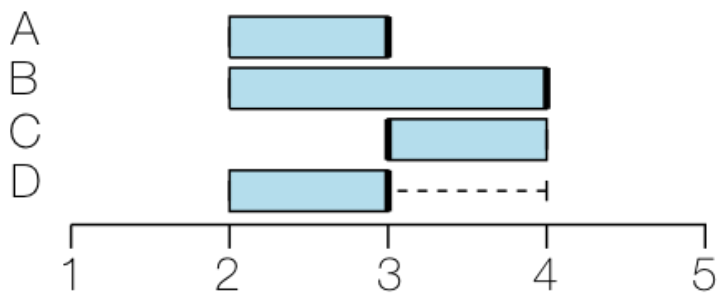

Was it distracting?

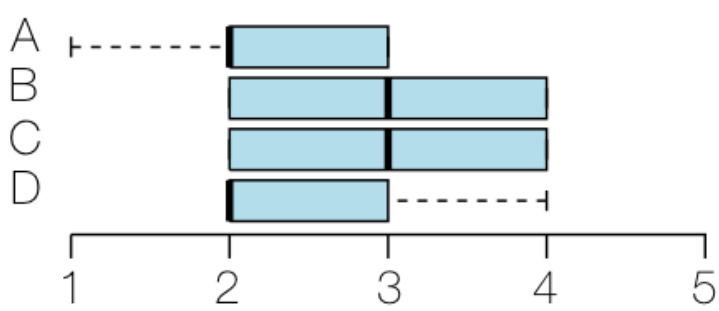

\section{Good indication of quality}

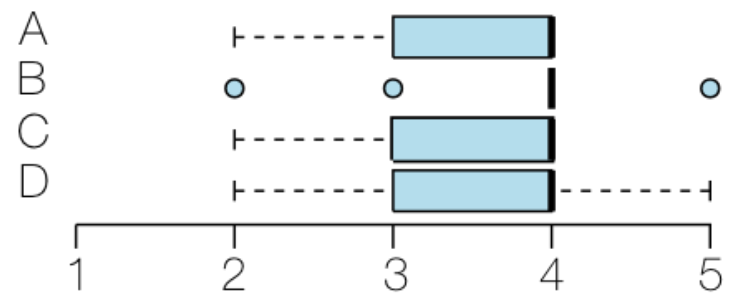

Good indication of balance

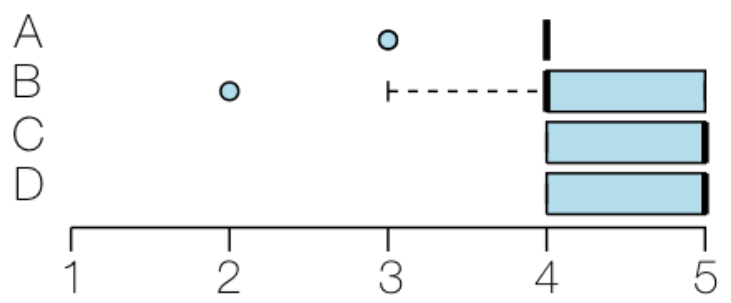

Figure 7 Results to the per-visualisation questionnaires $(N=12)$. All designs score well regarding clarity. $B$ and $C$ are most looked at and considered most distracting (C1Q1).

Discussion

Visualising quality and quantity of participation in a "design critique" session to pursue balance among all participating groups is promising, but challenging. Students perceive the visualisations as useful for discussions and they can promote activity in the classroom, but do 
not necessarily push towards a balanced distribution of feedback. Currently the designs are experienced as rewarding for over-participation and visually "punishing" for underparticipation: for instance, versions A, B and C are experienced as "bigger is better". Size and length are good indicators for quantity, but quantity is not the main message the visualisations should pass. Visualisation D does not use size as a quantity indicator, but suffers from a similar problem: students perceive a dot position within the circle (above average) as better, while a location outside the circle is experienced negatively as distance grows between under- and over-participators. This gap may seem insurmountable as time goes on, resulting in students giving up on trying to catch up.

Visualisation D was most preferred but was experienced as most uncomfortable by underparticipators. This is not necessarily a bad thing. The challenge will be to transform this perception so that i) under-participators experience it as motivation instead of pressure, and ii) over-participators understand they should leave room for others to contribute.

In the current experiment, we visualise inter-group activity. Intra-group, i.e. per-student activity can be visualised in a similar manner, opening up more possibilities for learning settings. Future work will explore the design changes required to accommodate larger numbers of individual subjects. The visual nature of both version $\mathrm{C}$ and $\mathrm{D}$ can for instance be used in a multi-focused visualisation: inside the dot representing a group, the visualisation can be repeated with information on the individual group members. This could provide interesting insights in both intra- and inter-group activity simultaneously.

We presented four AIVs designs to display the balance of feedback in a "design critique" session with a classroom of students. These designs have the potential to impact feedback distribution in the classroom, but are not yet experienced positively by under-participating students. Our next case study will explore how we can tackle this perception, and look more into detail on how an AIV can affect the participation in classroom discussions.

\section{Case Study 2: Promoting Balance}

\section{Design Improvements}

In our second case study, we attempt to improve the visualisation to help tone down overparticipation and motivate under-participators. We start from design D: During the first case study it was preferred by students, was not considered very distracting but was experienced most uncomfortable by under-participators. To improve D so that i) under-participators experience it as motivation instead of pressure, and ii) over-participators understand they should leave room for others to contribute, we give "balance" a broader meaning: DiMicco \& Bender (2007) define an under- and over-participation static limit around the average (e.g. 25\% of participation for four participants). Similarly, we define a "balanced" area by adding an upper and lower limit. However, in our case, the upper and lower limits alter depending on the current, live average of the feedback in the classroom:

$$
l_{t}=p * \sum_{i=1}^{N} \frac{f_{i t}}{N}
$$

where $l$ is the (upper/lower) limit at a specific time $t, N$ is the number of groups and $f_{i t}$ is the total amount of feedback given by group $i$ at a specific $t . p$ is a percentage which defines how far the bounds may deviate from the live average. The bounds will thus change over time, allowing more leeway for groups as time goes by (e.g. being one minute under an average of 
five minutes of total feedback is a greater imbalance than being one minute under an average of 20 minutes).

Figure 8 shows the updated version of D where a zone is created in which "balance" is achieved, i.e. the static middle (green) circle depicts the average of feedback, while the inner and outer (orange) circles show the upper- and lower-bounds.

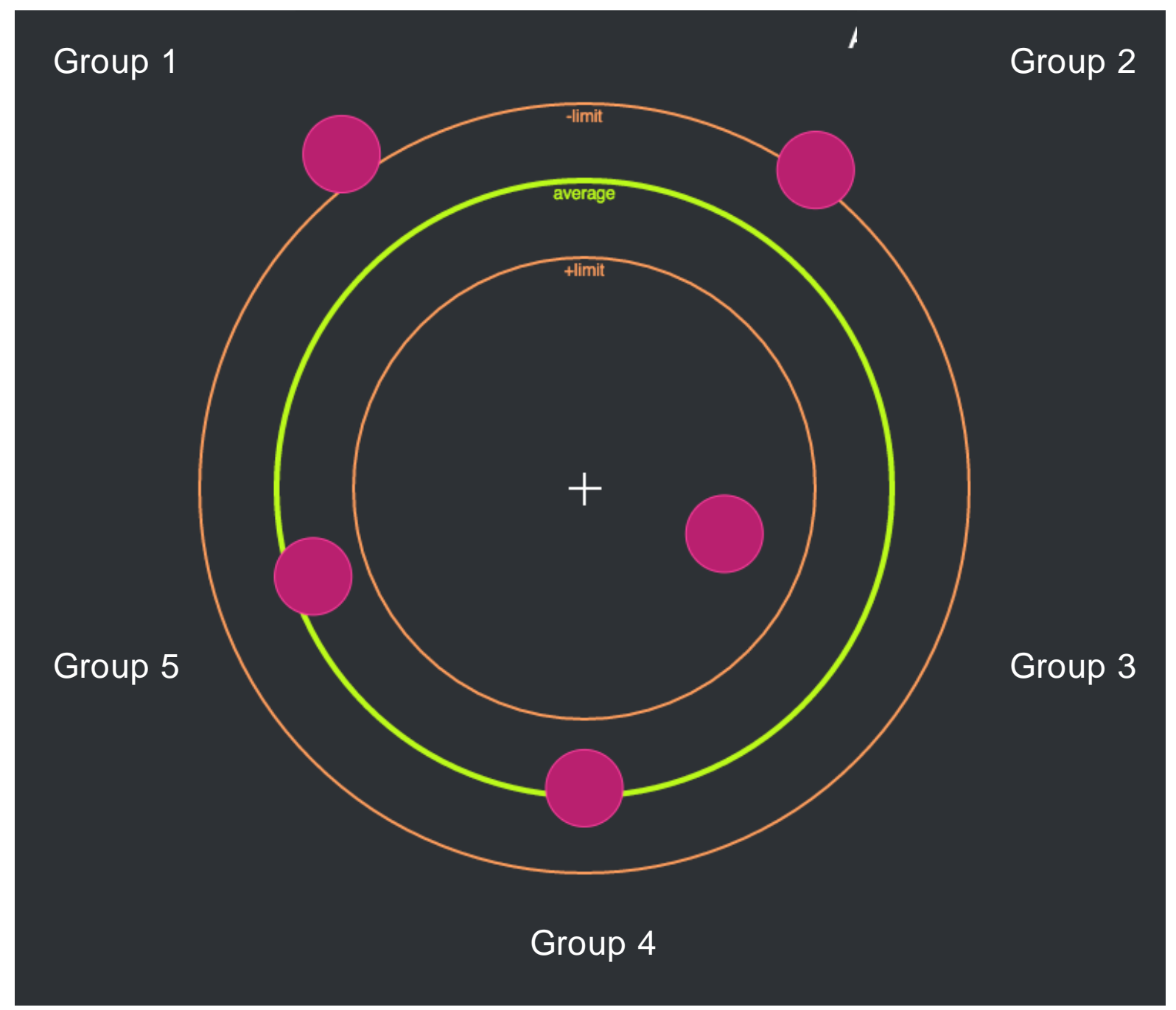

Figure 8 Design D, improved with boundaries in which balance is achieved.

\section{Evaluation}

\section{Experiment Setup}

19 students ( $2 \mathrm{~F}$, age 21-23, no overlap with the first case study) participated in the evaluation during a four hour long FCHI course at KU Leuven. Six groups (five groups of three, one group of four students) each gave a 15-minute presentation on the intermediate results of their project work. After each presentation, 15 minutes were reserved for all groups in the audience to provide feedback and ask questions. During this case study, the teacher assistant only tracked student feedback, meaning the AIV did not visualise information regarding the teacher. Instead of students rating peers through "likes", the teacher rated and logged the quality of the feedback given. This data was kept hidden from the students during the experiment. For a better aesthetic integration with the environment (Pousman \& Stasko 2006), the large screen was replaced by a projected version on the wall next to the presenting students. 
First, all students were asked to fill in a questionnaire (C2Q1) regarding their view on the importance of peer feedback. Six 7-scale Likert questions were asked (1-strongly disagree, disagree, somewhat disagree, neither agree nor disagree, somewhat agree, agree, 7 -strongly agree):

C2Q1.1. It is important to give feedback.

C2Q1.2. Feedback of the professor is more important than peer feedback.

C2Q1.3. It is important that our group gives the most feedback.

C2Q1.4. I do not care that we give few feedback.

C2Q1.5. It is important that all groups give equal feedback.

C2Q1.6. I am well aware of the distribution of feedback across groups.

Another two 5-scale Likert questions were asked (1-never, rarely, occasionally, a moderate amount, 5-a great deal):

C2Q2.1. How often do I give feedback?

C2Q2.2. How often should our group give feedback?

At the beginning of the sessions, students were made aware that there should be a balanced distribution of feedback among groups. During the first three presentations, no visualisation was shown. During the three last presentations, the improved visualisation D was projected on a wall next to the presenting students. The upper- and lower-bounds that define a "balanced" session were set at $20 \%$ distance from average (Joan DiMicco \& Bender (2007) set the range to $50 \%$ of the static average). This means that after a total of one minute of feedback is reached, groups would be expected to be within twelve seconds of the total average. At an average of ten minutes of feedback, groups are allowed to deviate as far as two minutes.

After the first three presentations without visualisation and the next three presentations supported by the visualisation, students had to answer two questions regarding their awareness of the amount of feedback given during these three presentations (C2Q2). At the end of the sessions, students filled in a final questionnaire with six 7-scale Likert questions (1-strongly disagree, 7-strongly agree) and one 5-scale Likert question (1-never, 5-a great deal) regarding their perception of the AIV (C2Q3):

C2Q3.1. The visualisation was distracting

C2Q3.2. The visualisation helped me realise how much our group participated

C2Q3.3. The visualisation is useful to create feedback balance

C2Q3.4. The visualisation played an important role to create feedback balance

C2Q3.5. The visualisation was motivating

C2Q3.6. The visualisation was demotivating

C2Q3.7. How often did I look at the visualisation?

\section{Results}

Based on the questionnaire C2Q1 (see Figure 9), students remain neutral to whether or not they know how balanced the feedback is, but do have a small preference towards seeing balance. The professor's feedback is considered more important, but they still consider giving feedback an important activity, even though most students admit they do not give a lot of feedback. The amount of feedback their group gives should not be a lot, and they are indifferent towards low participation on their behalf. 
Questionnaire C2Q3 (see Figure 10) shows that students did find that the AIV helps them with awareness regarding their own contributions. Comparing their participation assumptions (C2Q2) with the logged data, two groups overestimated their efforts in the sessions without the AIV. The two under-participating groups estimated their efforts correctly. For the sessions where the AIV was present, two groups overestimated and four estimated correctly.

\section{Pre-Questionnaire}
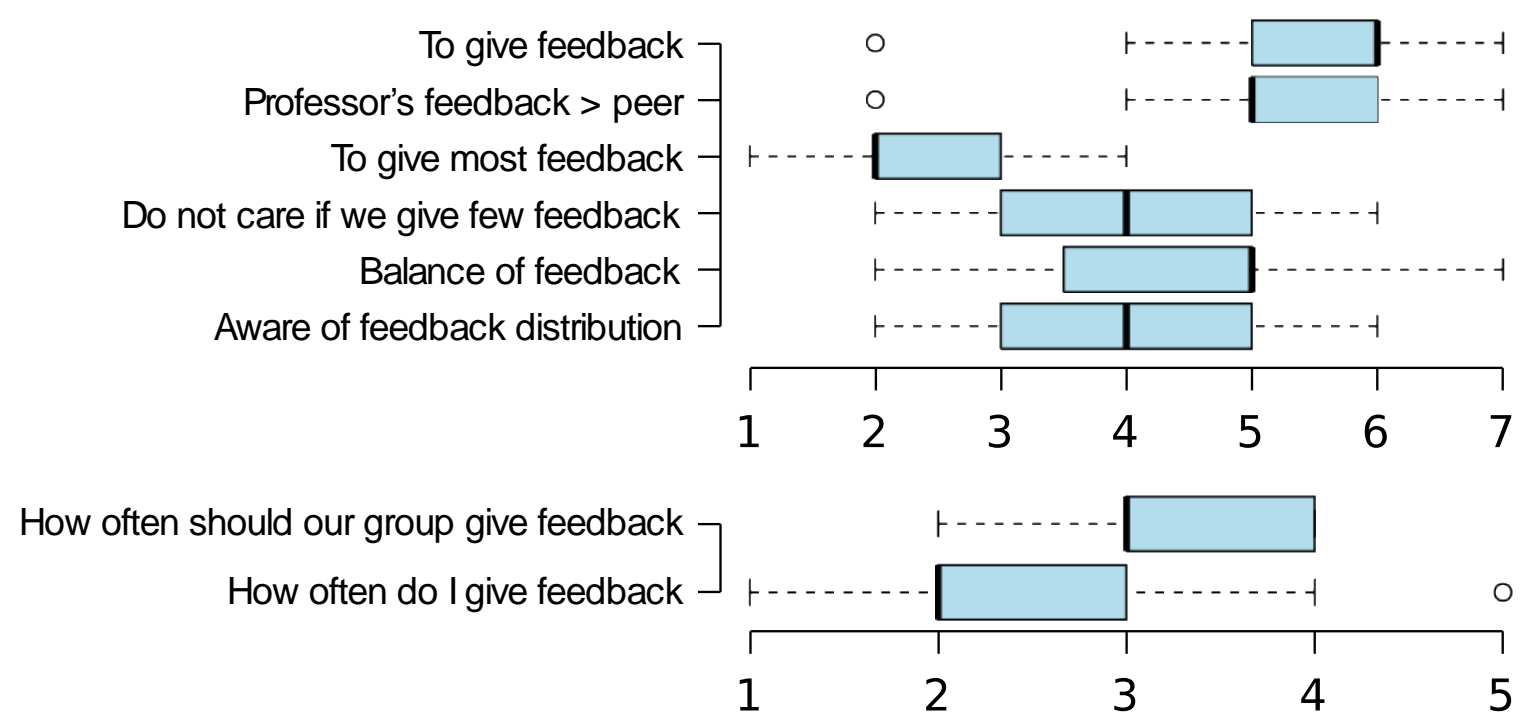

Figure 9 Questionnaire asked at the start of the classroom session ( $N=19)$ (C2Q1)

Students mostly disagreed that the AIV is useful for balance, and were neutral towards its importance for maintaining balance. They found the AIV a little distracting. It did help somewhat with motivation and was not considered demotivating.

The ratings for feedback contribution registered by the teacher showed that quality remained equally good for all feedback sessions. Students still made meaningful contributions and asked interesting questions with the presence of the AIV. 


\section{Post-Questionnaire}

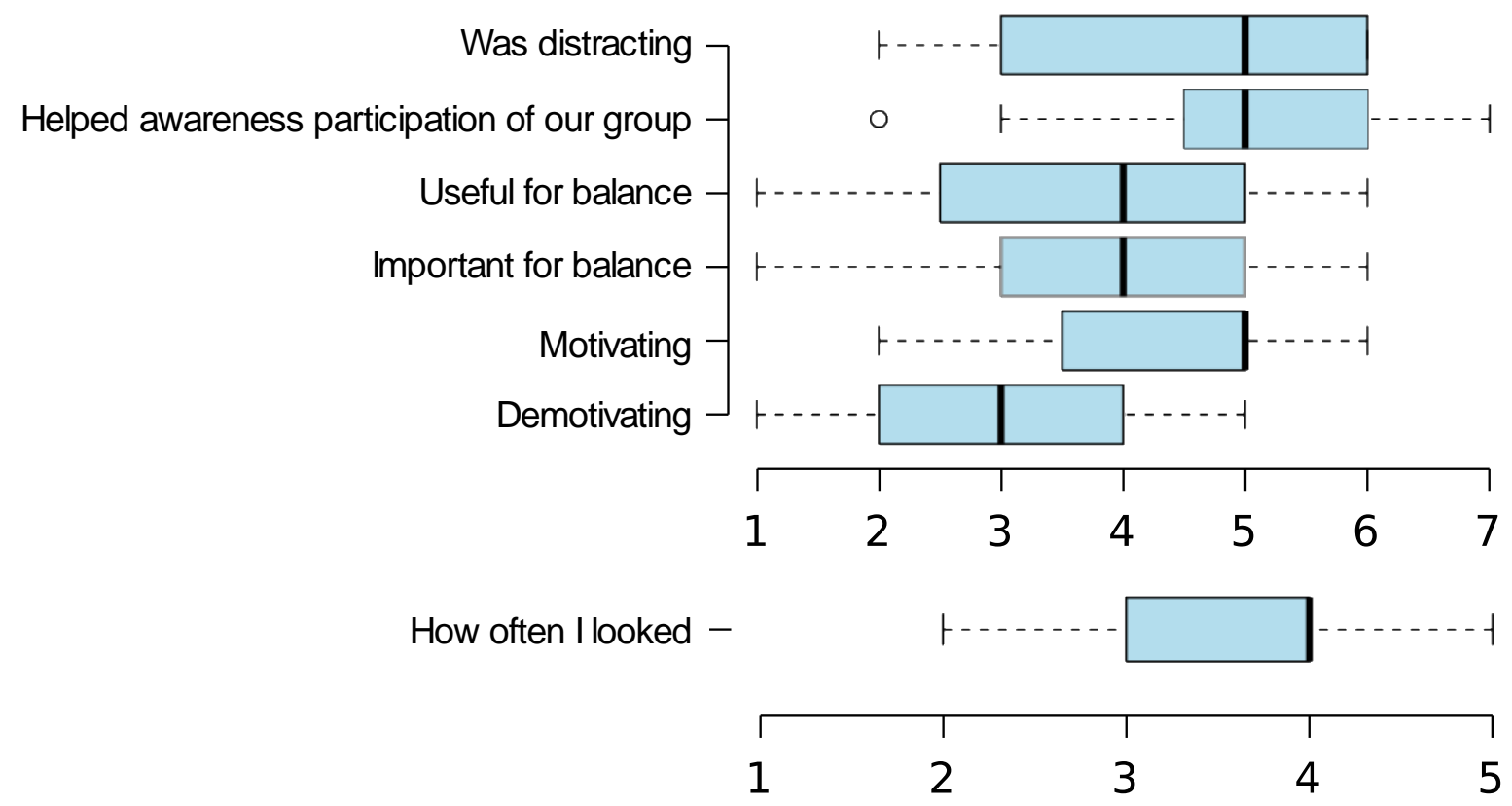

Figure 10 Post classroom session questionnaire (N=19) (C2Q3)

\section{Discussion}

AIVs can assist students in remaining aware of their contributions during a "design critique" session. Students do not specifically consider balance overly important, but understand the importance of giving peer feedback. The students claim to be aware of their low feedback contribution, but are indifferent to this. Therefore, the perceived motivational aspect of the dashboard can be of benefit to affect participation in the classroom. Section 6 will elaborate on this effect.

The updated D design was not considered demotivating. Broadening the range of what is considered "balance" lowered the visual distance an under-participator has from the average, which could lower the feeling of not being able to "catch up". It also requires more over/underparticipating before a group leaves the "balanced" zone. Students did still report that the visualisation had a more positive connotation with over-participation. This might be related to the labels used in the design (+limit, -limit, see Figure 8). Removing the positive and negative symbols from the upper- and lower bounds could resolve this issue, but makes it less obvious whether a group is under- or over-participating (e.g. "did I give too much or too little feedback").

As only duration of feedback is taken into consideration, it could be expected that students will attempt to game the system. However, the ratings of feedback contributions captured by the teachers showed that the presence of the AIV did not have a negative effect on the quality of feedback contribution. As well thought-out questions and feedback would take longer to explain, the quantity visualised for such a contribution could be an indication of its quality. As the feedback occurs in a public setting, the barrier to gaming the system is higher: teachers and students might easily see through these attempts and intervene. 


\section{Effect on Feedback Balance}

During both case studies, all activity was logged in a MongoDB database for further analysis. This section investigates the feedback participation distribution observed during the two case studies.

Total Feedback Participation

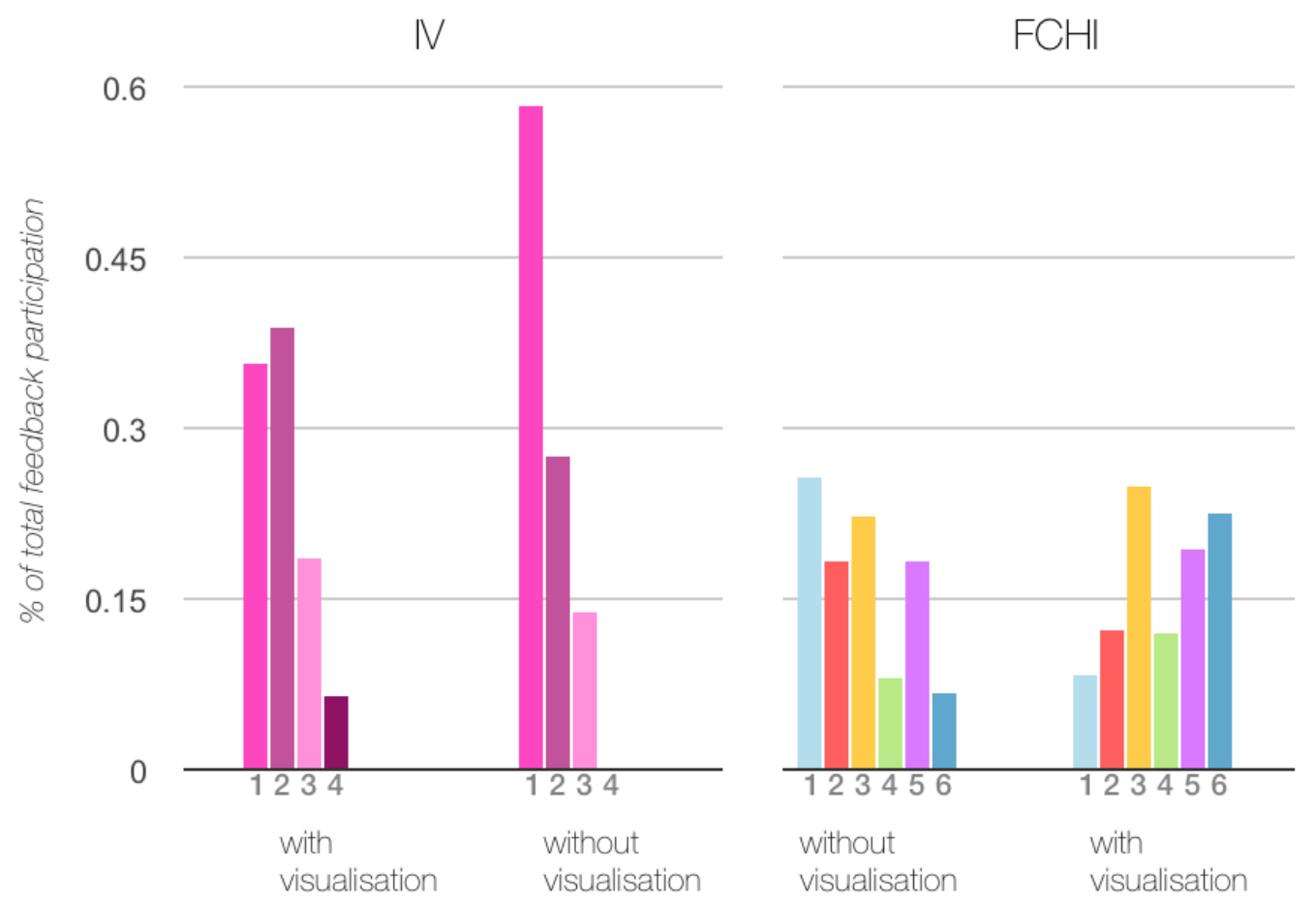

Figure 11 Percentage of the total feedback participation per group. Left: During the IV course, all four groups participated when the AIV is present. One group (number four) does not participate when AIV is not present. Right: During the FCHI feedback sessions, all six groups participate with and without AIV present. 

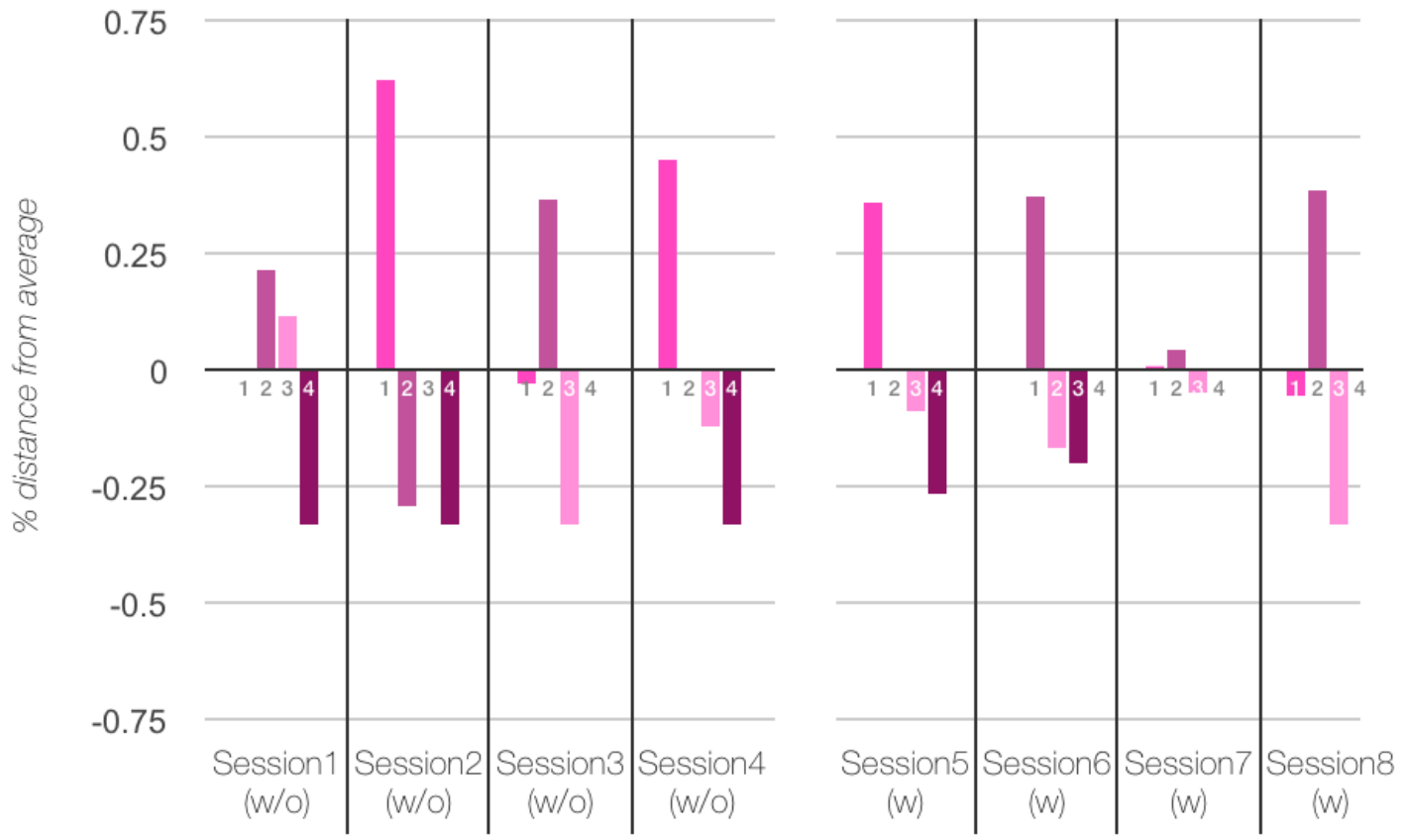

Figure 12 Distribution of participation among groups in IV. Each bar per session represents a student group. Left: four feedback sessions without (w/o) the AIV. Right: four feedback sessions with (w) AIV.

Feedback Participation Balance (FCHI)

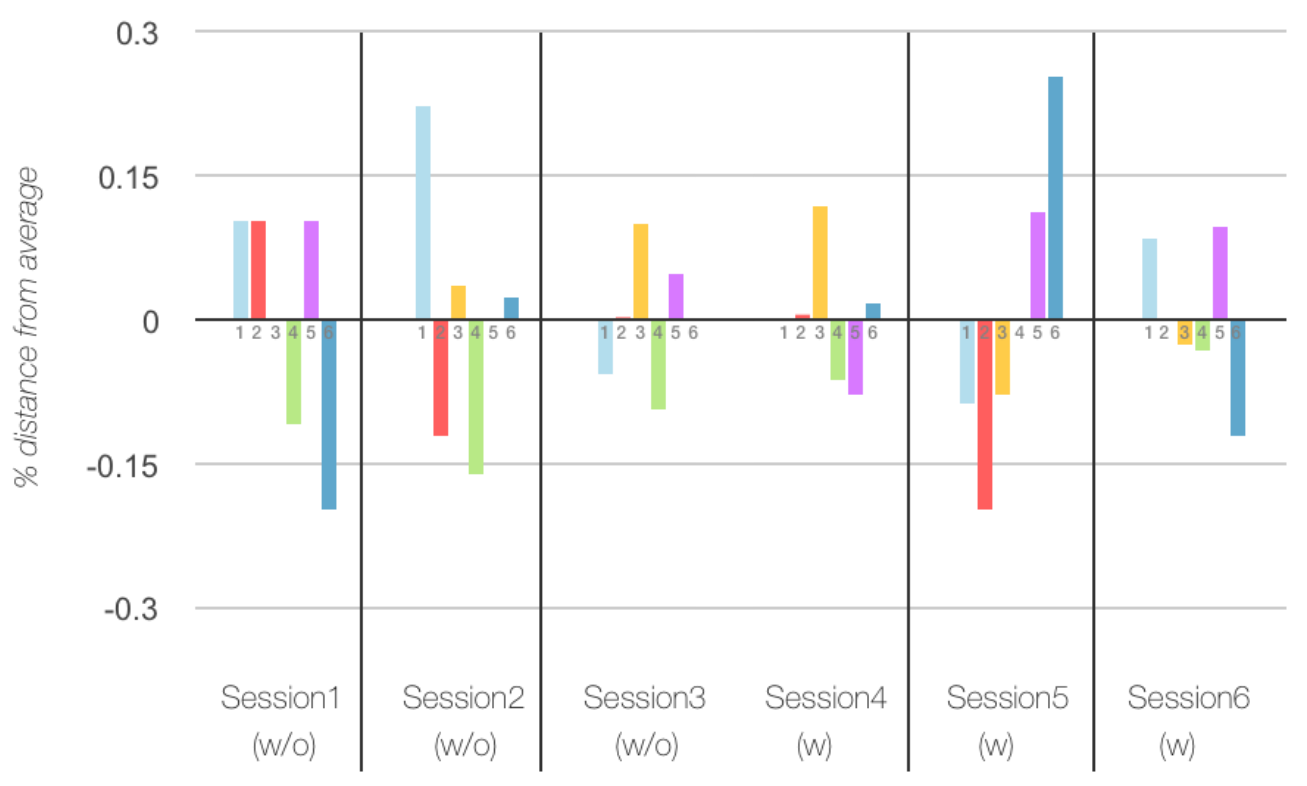

Figure 13 Distribution of participation among groups in FCHI. Each bar per session represents a student group. Left: three feedback sessions without (w/o) AIV. Right: three feedback sessions with (w) AIV..

Figure 11 gives an overview of the feedback participation with and without the AIV in both the IV course session (first case study) and the FCHI course session (second case study). During the first case study, when students were not specifically asked to keep the feedback 
balanced, a session with the AIV caused all groups to participate. During the session without the visualisation, the under-participating group did not participate at all.

During the second case study, where students were specifically asked to participate in a balanced way, all groups participated, with or without the AIV. When comparing the balance of the IV session (see Figure 12) with the balance of the FCHI session (see Figure 13), the distribution of feedback is more balanced: deviation from the average in the IV course goes up to $60 \%$ without the AIV and goes above $30 \%$ with. Groups of the FCHI course remain mostly within the range of $10 \%$, with active groups reaching just above $20 \%$. Groups who reported they found balance important, remain closer to the average than those who did not.

Comparing the two presentations with the highest numbers of feedback contributions (i.e. the number of times a group gives feedback or asks a questions), there is a difference in how fast the classroom merges towards balance. In the FCHI session without the AIV (see Figure 14 top, 30 contributions) three groups remain very active while two groups (red and green) only "catch up" towards the end. In the active FCHI feedback session (see Figure 14 bottom, 40 contributions) with the AIV, all groups contribute quite early in the session, creating a balance much quicker.

There is an indication that the AIV could initiate quicker interaction from under-participators. The visual feedback seems to influence their choice-of-acting faster. The visualisation can help realise that waiting longer to give feedback makes "catching up" harder. 

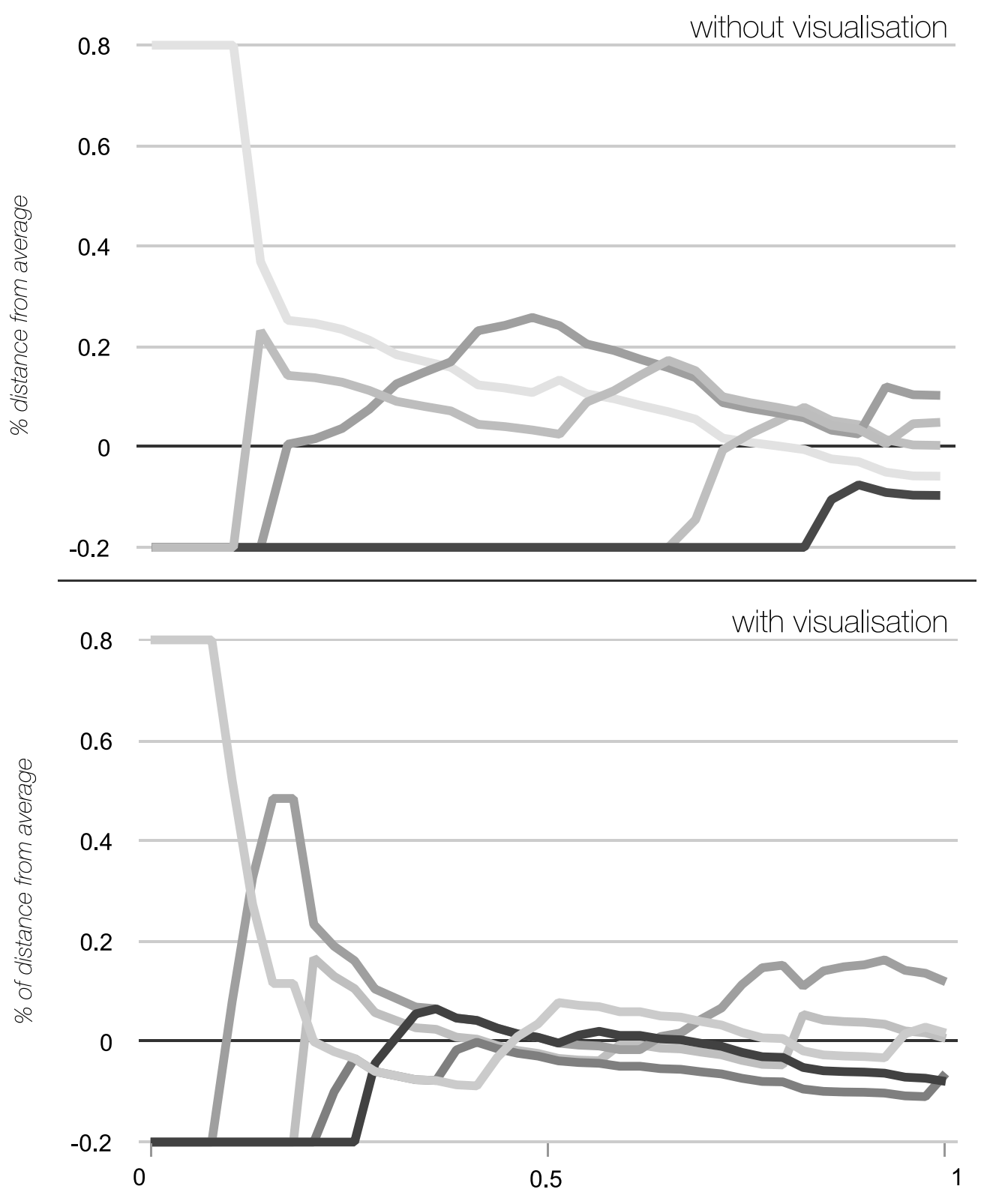

$\%$ of time of feedback session passed

Figure 14 Convergence towards feedback balance without the AIV (top) and with the visualisation (bottom) during the two most active feedback sessions of FCHI. 


\section{General Discussion}

Our case studies have shown that it is possible to impact balanced participation in "design critique" sessions through the use of an AIV of feedback participation. This section breaks down our findings per research question.

\section{What are the design challenges for AIVs to promote balanced group participation in classrooms, and how can they be met? (RQ1)}

Visualise balance in an abstract and neutral way: Abstracting learning analytics data to the essential message one wishes to pass helps motivate students (Santos et al., 2013). From our designs we learned that focussing on a visualisation that represents balance as an abstracted quantity created better results. By creating a broader representation of what is considered balance, the perception of motivation was improved. By visually lowering the gap between under- and over-participation, and thus creating a less accurate representation of the real data, under-participators are less demotivated. It is also important to create a neutral visualisation: removing negative connotation with under-participation and positive connotation with overparticipation can help tone down over-participators and have less demotivating effect on underparticipators, resulting in a better user acceptance.

Add the qualitative dimension to the visualisation: Quality through the use of "likes" was perceived as motivational. Small amounts of feedback of great quality will most likely be more meaningful than lots of low quality contributions (e.g. not receiving "likes"). Therefore, merging the quantitative and qualitative parameters so that one impacts the other (e.g. average equals a calculation of both parameters) must be further explored. Future work should also take into account that not only the AIV, but also the interaction with peer feedback (e.g. "liking" contributions), can impact participation in feedback sessions. Adding teacher's real-time feedback rating to the visualisation is another interesting path to explore.

Create a realistic picture of the classroom situation: When limiting the visualisation to the duration of feedback in the FCHI course, no negative impact on feedback quality was observed. However, some students did report a fear of a detrimental effect on quality of feedback. Capturing more types of learner tracers can create a better picture of the students' contributions in the classroom, such as eye gaze and body (Raca \& Dillenbourg, 2013). With this extra information, it still is important and challenging to keep IC and NL low.

\section{Are visualisations on AIVs effective means for creating balanced group participation in classroom settings? (RQ2)}

AIVs raise awareness of the invisible: The case studies have shown that it is possible to motivate under-participators and make clear to over-participators to leave room for others to participate. Such peer awareness is not straightforward, as one of the over-participating groups confirmed: "We realize now that we give (too) much feedback, and will now also listen more to others". While AIVs can help raise awareness of peer activities (Dillenbourg et al., 2011), classroom layout plays an important role on the type of devices that are suited. In our case, students face the direction of the presenter. Students in the back might have a harder time to get the attention of the presenter. This problem could be eliminated by e.g. using a U-shaped table configuration in the classroom, however, this is not always feasible. The AIV can help "front-row" students become aware of the under-participation of students around them (which is harder to notice without turning around). 
Ambient feedback information can activate students: There are indications that, in active feedback sessions, convergence to balance is achieved quicker with the presence of the visualisation. While a better balance is achieved by merely asking students to participate more, the presence of the visualisation resulted in all groups participating quicker. The visualisation can thus have a positive effect on more active contribution, keeping students on their toes through the entire session. The presence of AIVs and its effect on "competition" is not new: Shelf (Dillenbourg et al., 2011) similarly caused students to be more competitive. Future work should attempt to leverage this effect to activate and motivate students which could result in more endurance during classroom sessions.

AIV as support for teacher/presenter: Tracking and visualising student activities can help teachers with classroom orchestration (Martinez-Maldonado et al., 2014). Having a better overview of the balance situation, can help with the choice of which groups should be allowed to provide feedback next. This can help the presenter give equal chances to everyone in the audience, but also help teachers to manually intervene and "nudge" under-participators to join in the discussion. It can be argued that, with a moderator, there is only need for personal (teacher/presenter) dashboards. However, as Klerkx et al. (2016) frame it: If learners are always told what to do next, then how can we expect them to possess the typical 21st century skills of collaboration, communication, critical thinking and creativity?

\section{Conclusion}

A balanced participation between learners is important for achieving intended learning outcomes. This paper explored the use of AIVs to improve the balance between groups during "design critique" studio sessions. Four visualisation designs were deployed and evaluated in a course on Information Visualisation. This helped explore (RQ1) the design challenges to create balanced group participation in classrooms. While low distraction and good aesthetics are required to create an AIV suitable for the classroom, the way in which "balance" is visualised plays an important role in helping under-participators provide more feedback, and overparticipators tone down their contributions. Creating a broader interval in which "balance" is defined, can positively impact motivation. Visually "punishing" over-participation similar to under-participation helps groups become aware of and reflect on their over-participation.

The resulting visualisation was deployed and evaluated in the course Fundamentals of Computer-Human Interaction (FCHI) to see whether (RQ2) AIVs are an effective means for creating balanced group participation. The visualisation does help students with awareness of their participation. As students report preference towards a balanced situation, the visualisation can assist them to reach this goal. The AIV did not impact quality of feedback contributions. During active feedback sessions, the AIV helped the groups converge quicker to a balanced situation.

As such, the contribution of the paper is two-fold: i) it presents necessary design choices for AIVs that promote feedback balance in classrooms, motivating under-participators while limiting over-participation, and ii) it shows the effects on student perception and feedback participation through the actual deployment of such visualisations in "real classroom sessions". Future deployments in diverse group settings will help further investigate the impact of balance 
AIVs. We therefore invite researchers and practitioners to deploy these visualisations ${ }^{5}$ in other settings and share their findings.

\section{Bibliography}

Bachour, K., Kaplan, F., \& Dillenbourg, P. (2010). An interactive table for supporting participation balance in face-to-face collaborative learning. IEEE Transactions on Learning Technologies, 3(3), 203-213. http://doi.org/10.1109/TLT.2010.18

Bergstrom, T., \& Karahalios, K. (2007a). Conversation Clock: Visualizing audio patterns in co-located groups. In Proceedings of the Annual Hawaii International Conference on System Sciences (pp. 78-78). Washington, DC, USA: IEEE Computer Society. http://doi.org/10.1109/HICSS.2007.151

Bergstrom, T., \& Karahalios, K. (2007b). Conversation votes: enabling anonymous cues. Proceedings of ACM CHI 2007 Conference on Human Factors in Computing Systems, 2, 2279-2284. http://doi.org/http://doi.acm.org/10.1145/1240866.1240994

Bergstrom, T., \& Karahalios, K. (2007c). Seeing more: Visualizing audio cues. Most, 29-42. http://doi.org/10.1007/978-3-540-74800-7_3

Börner, D., Kalz, M., \& Specht, M. (2013). Beyond the channel: A literature review on ambient displays for learning. Computers and Education, 60(1), 426-435.

http://doi.org/10.1016/j.compedu.2012.06.010

Cha, S., Lee, M.-H., \& Nam, T.-J. (2016). Gleamy. In Proceedings of the TEI '16: Tenth International Conference on Tangible, Embedded, and Embodied Interaction - TEI '16 (pp. 304-307). New York, New York, USA: ACM Press. http://doi.org/10.1145/2839462.2839501

Dillenbourg, P., Zufferey, G., Alavi, H., Jermann, P., Do-lenh, S., \& Bonnard, Q. (2011). Classroom Orchestration: The Third Circle of Usability - Why is Paper Highly Usable in Classrooms? In CSCL 2011 Proceeding (Vol. I, pp. 510-517). Retrieved from http://infoscience.epfl.ch/record/168741/files/Classroom Orchestration: The Third Circle of Usability.pdf? version $=1$

DiMicco, J., \& Bender, W. (2007). Group Reactions to Visual Feedback Tools. In Y. de Kort, W. IJsselsteijn, C. Midden, B. Eggen, \& B. J. Fogg (Eds.), Persuasive Technology (Vol. 4744, pp. 132-143). Springer Berlin Heidelberg. http://doi.org/10.1007/978-3-54077006-0_18

DiMicco, J., \& Bender, W. (2007). Group Reactions to Visual Feedback Tools. Persuasive Technology, 132-143. Retrieved from http://dx.doi.org/10.1007/978-3-540-77006-0_18

DiMicco, J. M., Pandolfo, A., \& Bender, W. (2004). Influencing Group Participation with a Shared Display. In Proceedings of the 2004 ACM Conference on Computer Supported Cooperative Work (pp. 614-623). New York, NY, USA: ACM. http://doi.org/10.1145/1031607.1031713

Eades, P., \& Shen, X. (2004). MoneyTree : Ambient Information Visualization Of Financial Data. Proceedings of the Pan-Sydney Area Workshop on Visual Information Processing (VIP'03), 01, 15-18. http://doi.org/http://portal.acm.org/citation.cfm?id=1082121.1082124

Fujinami, K., Kawsar, F., \& Nakajima, T. (2005). AwareMirror: A Personalized Display Using a Mirror. In Proceedings of the The 3rd International Conference on Pervasive Computing (pp. 315-332). http://doi.org/10.1007/11428572_19

Green, P., \& Wei-Haas, L. (1985). The rapid development of user interfaces: Experience with

${ }^{5}$ https://github.com/svencharleer/larae.talktalk 
the wizard of oz method. In Proceedings of the Human Factors and Ergonomics Society Annual Meeting (Vol. 29, pp. 470-474).

Hinrichs, U., Fisher, D., \& Riche, N. H. (2010). ResearchWave. In Proceedings of the 8th ACM Conference on Designing Interactive Systems - DIS '10 (p. 31). New York, New York, USA: ACM Press. http://doi.org/10.1145/1858171.1858177

Klerkx, J., Verbert, K., \& Duval, E. (2016). Learning Analytics Dashboards. In C. Lang \& G. Siemens (Eds.), Handbook of Learning Analytics \& Educational Data Mining (Accepted).

Lamberty, K. K., Froiland, K., Biatek, J., \& Adams, S. (2010). Encouraging awareness of peers' learning activities using large displays in the periphery. In Proceedings of the 28th of the international conference extended abstracts on Human factors in computing systems - CHI EA '10 (p. 3655). New York, New York, USA: ACM Press. http://doi.org/10.1145/1753846.1754034

Lee, K., Tsai, P.-S., Chai, C. S., \& Koh, J. H. L. (2014). Students' perceptions of selfdirected learning and collaborative learning with and without technology. Journal of Computer Assisted Learning, 30(5), 425-437.

Li, L., Liu, X., \& Steckelberg, A. L. (2010). Assessor or assessee: How student learning improves by giving and receiving peer feedback. British Journal of Educational Technology, 41(3), 525-536. http://doi.org/10.1111/j.1467-8535.2009.00968.x

Marques, A. M., Krejci, R., Siqueira, S. W. M., Pimentel, M., \& Braz, M. H. L. B. (2013). Structuring the discourse on social networks for learning: Case studies on blogs and microblogs. Computers in Human Behavior, 29(2), 395-400. http://doi.org/10.1016/j.chb.2012.03.001

Martinez-Maldonado, R., Clayphan, A., Yacef, K., \& Kay, J. (2014). Towards providing notifications to enhance teacher's awareness in the classroom. Lecture Notes in Computer Science (Including Subseries Lecture Notes in Artificial Intelligence and Lecture Notes in Bioinformatics), 8474 LNCS, 510-515. http://doi.org/10.1007/978-3319-07221-0_64

Martinez-Maldonado, R., Kay, J., Yacef, K., \& Schwendimann, B. (2012). An Interactive Teacher's Dashboard for Monitoring Groups in a Multi-tabletop Learning Environment. In S. Cerri, W. Clancey, G. Papadourakis, \& K. Panourgia (Eds.), Intelligent Tutoring Systems (Vol. 7315, pp. 482-492). Springer Berlin Heidelberg. http://doi.org/10.1007/978-3-642-30950-2_62

Miller, T., \& Stasko, J. (2002). Artistically conveying peripheral information with the InfoCanvas. In Proceedings of the Working Conference on Advanced Visual Interfaces $A V I$ '02 (p. 43). New York, New York, USA: ACM Press. http://doi.org/10.1145/1556262.1556268

Mirlacher, T., Buchner, R., Förster, F., Weiss, A., \& Tscheligi, M. (2009). Ambient Rabbits Likeability of Embodied Ambient Displays. In Lecture Notes in Computer Science (including subseries Lecture Notes in Artificial Intelligence and Lecture Notes in Bioinformatics) (Vol. 5859 LNCS, pp. 164-173). http://doi.org/10.1007/978-3-64205408-2_21

Nakahara, J., Hisamatsu, S., Yaegashi, K., \& Yamauchi, Y. (2005). iTree: Does the Mobile Phone Encourage Learners to Be More Involved in Collaborative Learning? In Proceedings of th 2005 Conference on Computer Support for Collaborative Learning: Learning 2005: The Next 10 Years! (pp. 470-478). International Society of the Learning Sciences. Retrieved from http://dl.acm.org/citation.cfm?id=1149293.1149354

Occhialini, V., Van Essen, H., \& Eggen, B. (2011). Design and evaluation of an ambient display to support time management during meetings. Lecture Notes in Computer Science (Including Subseries Lecture Notes in Artificial Intelligence and Lecture Notes 
in Bioinformatics), 6947 LNCS(PART 2), 263-280. http://doi.org/10.1007/978-3-64223771-3_20

Paulus, P. B., \& Dzindolet, M. T. (1993). Social influence processes in group brainstorming. Journal of Personality and Social Psychology. http://doi.org/10.1037/00223514.64.4.575

Pavlou, A., \& Kyza, E. a. (2013). An investigation of two methods for the technological mediation of collaborative peer feedback in higher education. Lecture Notes in Computer Science (Including Subseries Lecture Notes in Artificial Intelligence and Lecture Notes in Bioinformatics), 8095 LNCS, 274-287. http://doi.org/10.1007/978-3642-40814-4_22

Pentland, A. S., Hinds, P., \& Kim, T. (2012). Awareness as an antidote to distance: making distributed groups cooperative and consistent. Proceedings of the ACM 2012 Conference on Computer Supported Cooperative Work CSCW 12, 1237. http://doi.org/10.1145/2145204.2145391

Pousman, Z., \& Stasko, J. (2006). A Taxonomy of Ambient Information Systems: Four Patterns of Design. In Proceedings of the Working Conference on Advanced Visual Interfaces (pp. 67-74). New York, NY, USA: ACM. http://doi.org/10.1145/1133265.1133277

Raca, M., \& Dillenbourg, P. (2013). System for Assessing Classroom Attention. Proceedings of the Third International Conference on Learning Analytics and Knowledge - LAK '13. http://doi.org/10.1145/2460296.2460351

Salomon, G., \& Globerson, T. (1989). When teams do not function the way they ought to. International Journal of Educational Research, 13(1), 89-99. http://doi.org/http://dx.doi.org/10.1016/0883-0355(89)90018-9

Santos, J. L., Charleer, S., Parra, G., Klerkx, J., Duval, E., \& Verbert, K. (2013). Evaluating the Use of Open Badges in an Open Learning Environment. In Scaling up Learning for Sustained Impact (Vol. 8095 LNCS, pp. 314-327). http://doi.org/10.1007/978-3-64240814-4_25

Schiavo, G., Cappelletti, A., Mencarini, E., Stock, O., \& Zancanaro, M. (2014). Overt or subtle? Supporting group conversations with automatically targeted directives. In Proceedings of the 19th international conference on Intelligent User Interfaces - IUI'14 (pp. 225-234). http://doi.org/10.1145/2557500.2557507

Scott, P., Tomadaki, E., \& Quick, K. (2007). The shape of online meetings. The International Journal of Technology, Knowledge, and Society, 3(4), 1-16.

Siemens, G., \& Long, P. (2011). Penetrating the fog: Analytics in learning and education. In Educause Review (Vol. 46, pp. 30-32). Boulder, CO, USA: EDUCAUSE.

Skog, T., Ljungblad, S., \& Erik Holmquist, L. (2003). Between aesthetics and utility: Designing ambient information visualizations. In Proceedings - IEEE Symposium on Information Visualization, INFO VIS (pp. 233-240). IEEE. http://doi.org/10.1109/INFVIS.2003.1249031

Tausch, S., Steinberger, F., \& Hußmann, H. (2015). Thinking Like Disney: Supporting the Disney Method Using Ambient Feedback Based on Group Performance. In INTERACT 2015 INTERACT 2015, Part III, LNCS (Vol. 9298, pp. 614-621). http://doi.org/10.1007/978-3-319-22698-9_42

Tractinsky, N., \& Eytam, E. (2012). Considering the Aesthetics of Ubiquitous Displays. In A. Krüger \& T. Kuflik (Eds.), Ubiquitous Display Environments (pp. 89-104). Springer Berlin Heidelberg. http://doi.org/10.1007/978-3-642-27663-7_6

van Tonder, B., \& Wesson, J. (2008). Visualisation of Personal Communication Patterns Using Mobile Phones. In Ifip International Federation For Information Processing (pp. 260-274). http://doi.org/10.1007/978-3-540-92698-6_16 
Verbert, K., Duval, E., Klerkx, J., Govaerts, S., \& Santos, J. L. (2013). Learning Analytics Dashboard Applications. American Behavioral Scientist, 57(10), 1500-1509. http://doi.org/10.1177/0002764213479363

Verbert, K., Govaerts, S., Duval, E., Santos, J., Van Assche, F., Parra, G., \& Klerkx, J. (2014). Learning dashboards: an overview and future research opportunities. Personal and Ubiquitous Computing, 18(6), 1499-1514.

Weiser, M., \& Brown, J. S. (1996). Designing Calm Technology. PowerGrid Journal, 1(1), 75-85. http://doi.org/10.1.1.135.9788

Wenger, E. (2011). Communities of practice: A brief introduction, 1-7. Retrieved from https://scholarsbank.uoregon.edu/xmlui/handle/1794/11736

Wisneski, C., Ishii, H., Dahley, A., Gorbet, M., Brave, S., Ullmer, B., \& Yarin, P. (1998). Ambient displays: Turning architectural space into an interface between people and digital information. Lecture Notes in Computer Science, 1370, 22-32.

http://doi.org/10.1007/3-540-69706-3_4 